\title{
Atrioventricular block secondary to a congenital aneurysm of the membranous septum Histological examination of conduction system
}

\author{
Cl. Thery, J. Lekieffre, and Cl. Dupuis \\ From the Service de Cardiologie, Cité Hospitalière, and the Service de Cardiologie Pédiatrique, Hôpital Calmette, \\ University of Lille (France)
}

\begin{abstract}
Atrioventricular block which caused death in a 6-month-old baby is reported. Necropsy examination revealed the only abnormality in the heart to be an aneurysm of the membranous septum. Histological examination of the conduction system showed fibrosis and attenuation of the bundle of His at the lower border of the aneurysm.
\end{abstract}

Several authors have reported atrioventricular block in patients with aneurysms of the membranous ventricular septum. The role of the aneurysm itself in the genesis of conduction defects has, however, never been absolutely established. Most reports do not include any study of the conduction system. In the only two cases where histological study was carried out, the patients were over 60 years of age when the atrioventricular block appeared, and, this being so, additional factors were likely to have been present. We are reporting a clinicopathological case where the atrioventricular block appeared shortly after birth and was secondary to destruction of the bundle of His, which was surrounded by the aneurysm.

\section{Case report}

A 6-week-old girl was admitted to hospital because of paroxysmal tachycardia. There was no previous history: both parents and two brothers were healthy. Her weight at birth was $2930 \mathrm{~g}$. In the week preceding admission the child showed digestive troubles, anorexia, and failure to gain weight. On admission there was cyanosis, enlargement of the liver, and a tachycardia of 200 a minute. Chest $x$-ray showed a slight increase in cardiac diameter but no obvious abnormality of outline. An electrocardiogram confirmed the tachycardia, which was of supraventricular type, with fusion of $P$ and $T$ waves. The child was given digitoxin for two days; the sinus rate came down to I0o a minute and the heart sounds were normal, but the electrocardiogram showed first degree atrioventricular block (PR $0.24 \mathrm{~s}$ ). When the child was examined again 3 months later, her general condition was good, and clinical and radiological examination was normal, but first degree atrioventricular block was still shown by the electrocardiogram. When 6 months old she was admitted again because of a bradycardia of 50 a minute. In the electrocardiogram (Fig. I) first degree atrioventricular block alternated with second degree Mobitz type I or II atrioventricular block and 2: I or higher degree of block. In spite of the administration of isoprenaline, the heart rate fell and the patient died during a syncopal attack before pacemaker stimulation could be tried.

The necropsy was carried out 20 hours after death. The heart weighed $50 \mathrm{~g}$. No anomaly was recorded except for an aneurysm of the lower part of the membranous septum: the aperture, $3 \mathrm{~mm}$ wide, opened under the commissure between the non-coronary and the right coronary aortic valve cusps. The aneurysm extended under the septal cusp of the tricuspid valve, and was $15 \mathrm{~mm}$ deep. With the exception of a slightly congested liver no other abnormalities were found.

\section{Histological examination of conduction system}

The interatrial and interventricular septa were sectioned from the posterior to anterior aspects, into 1520 eightmicron serial sections; I out of every Io was stained by the Trichrome of Masson stain. The atrioventricular node was normal (sections 610 to 720). The bundle of His penetrated at the bottom of the membranous septum, and had a normal morphology for this level. A few radiations of the posterior fasciculus of the left bundlebranch originated at this level (Fig. 2a) (sections 1000 to 1020). The aneurysm of the membranous septum on section I040 had its aperture in direct contact with the bundle of His which was pushed to the left and crescentic in shape, with the concave side to the right. In more anterior sections where the aneurysm was larger the bundle of His became stretched, attenuated, and atrophic (sections II20 to II80) (Fig. 2, b, c, d, e). At this level 


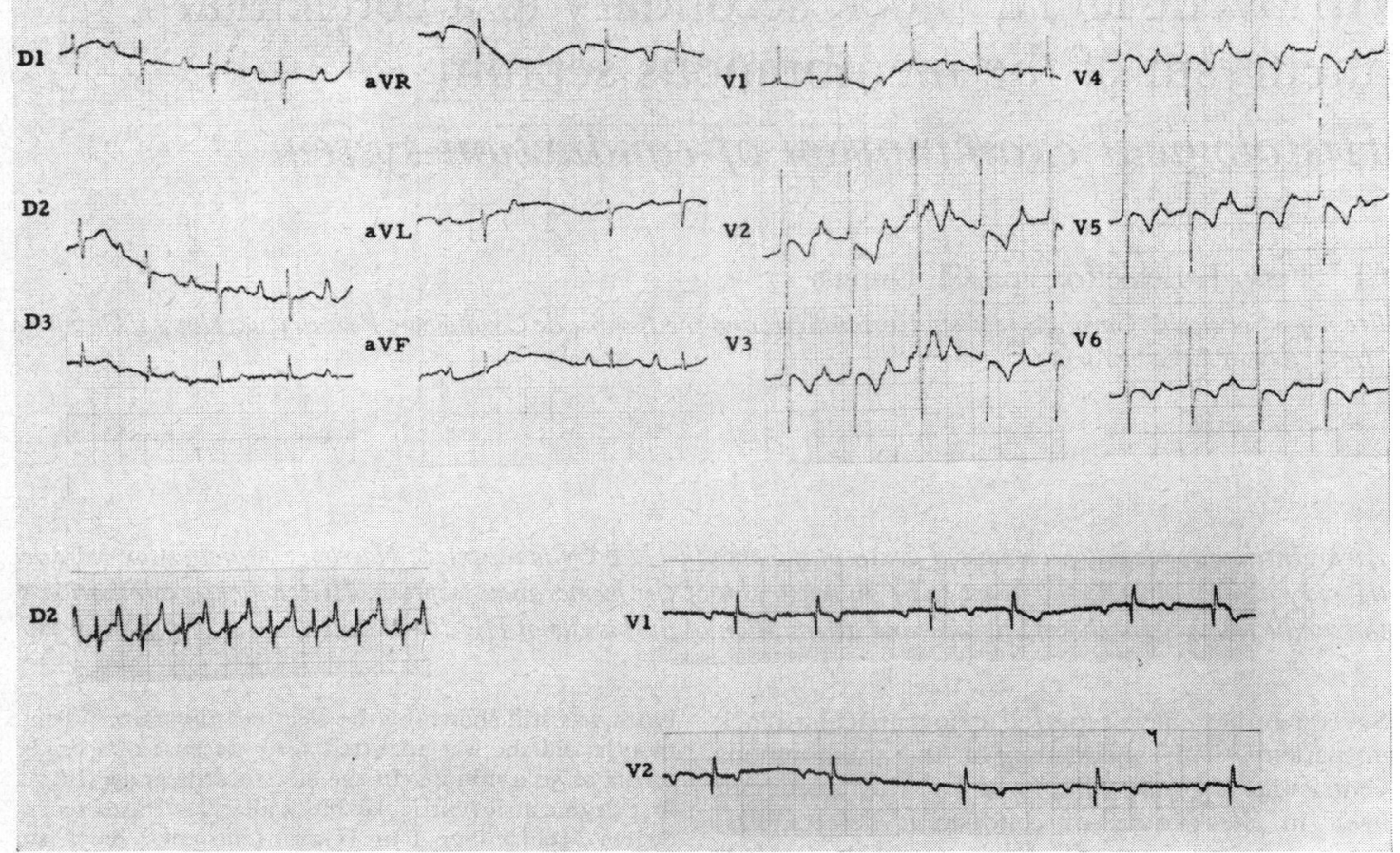

FIG. I Top: the electrocardiogram shows first degree and Mobitz type II atrioventricular block. Bottom: tachycardia of supraventricular type (left) alternating with periods of Mobitz type I and 2: I atrioventricular block (right). See the text.

the right bundle-branch separated from the main bundle, taking a subendocardial course, and the lower part of the aneurysmal sac was directly in contact with the first part of this branch (Fig. 2f). From section 1380 onward the right branch penetrated into the myocardium, and can be followed to its termination where it reaches the endocardium, without showing any change. The left branch (except for a few posterior radiations which separated from the bundle of His before the aneurysm) left the main bundle in sections II50 onward. The peripheral portions and the anterior, posterior, and central subdivisions of the left branch were normal.

\section{Discussion}

Aneurysms of the membranous septum are considered to be rare. Since the first description by Laennec in 1826, some 200 cases have been reported (Cuvillier, 1974). It may become a more frequently recognized malformation than published data suggest, since angiography now more frequently enables the diagnosis to be made in life. Many cases are clinically silent and discovered only by chance during angiography or necropsy. The aneurysms may, however, be complicated by perforation, bac- terial endocarditis, and aortic or tricuspid regurgitation; more rarely they may become thrombosed, or because of their size, obstruct ejection from the right ventricle.

Aneurysms of the membranous septum may also be complicated by arrhythmias or conduction disturbances, as in the present reported case. To our knowledge there are 7 previously reported cases of atrioventricular block ascribed to an aneurysm of the membranous septum. Craigie (I843) described a 38-year-old man who died suddenly after an episode of bradycardia; the necropsy demonstrated a nonperforated aneurysm as big as a walnut. Legg ( 1876 ) reported a similar case in a 60-year-old man. Clark and White (I952) reported a woman with a previous history of diphtheria who had shown, since the age of $2 \mathrm{I}$, atrioventricular block with fainting fits, and in whom the only anomaly found during necropsy was an aneurysm of the membranous septum, $1.8 \mathrm{~cm}$ in diameter. Rogers, Evans, and Domeier (1952) observed complete heart block two years before death in a 70-year-old hypertensive man who had shown many episodes of heart 


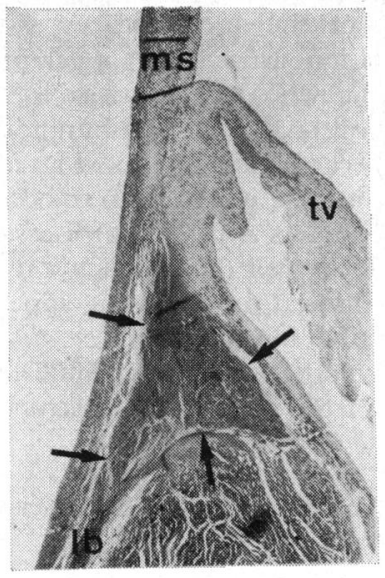

a

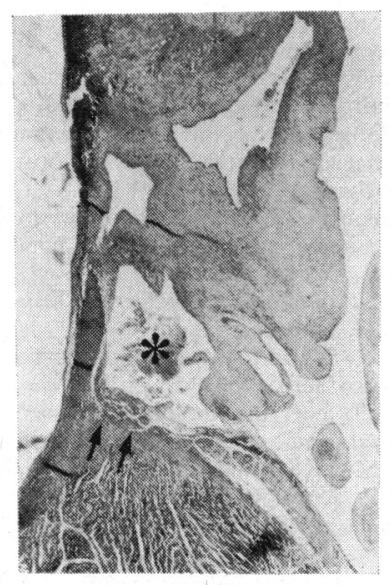

d

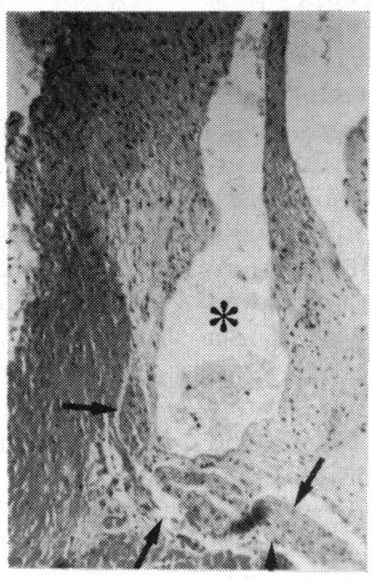

b

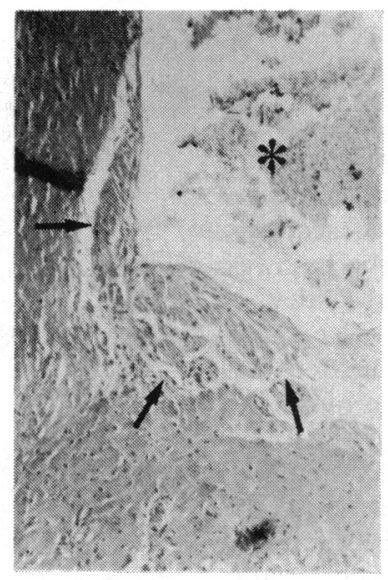

e

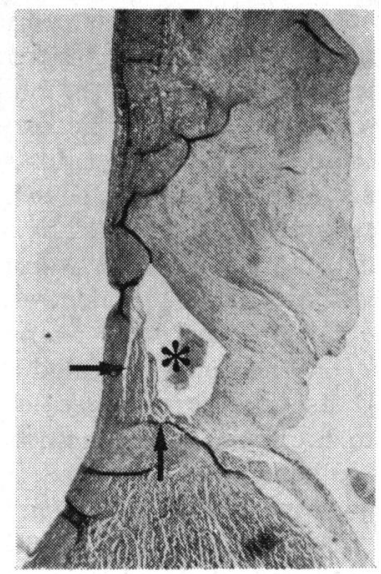

c

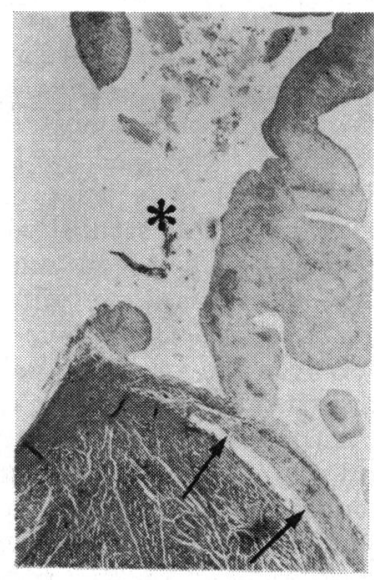

f

FIG. 2 a) Section 1000 ( $\times 16$ ). The bundle of His (arrowed) at the bottom of the membranous septum (ms) is normal at this level. Radiations of the posterior fasciculus of the left bundlebranch $(l b)$ arise at this level. $t v=$ tricuspid valve. b) Section $1040(\times 62)$. c) Section 1080 $(\times 16) . d)$ and $e)$ Section $1140(\times 16$ and $\times 62)$. The membranous septum, distended, is deeply hollowed by the aneurysm cavity $\left(^{\star}\right)$ which displaces the bundle of His (arrowed) downwards and to the left. This latter looks crescentic with its concave side to the right. The larger the aneurysm grows, the more atrophic the bundle of His becomes. $f)$ Section $1300(\times 16)$. Section at the level of the greatest diameter of the aperture of the aneurysm. The aneurysmal sac points towards the right and on the inferior margin impinges directly on the subendocardial section of the right bundle-branch.

failure; the necropsy showed severe atherosclerosis with an old myocardial infarction and an aneurysm of the membranous septum whose aperture measured $1.8 \times 1.5 \mathrm{~cm}$. Larsen and Noer (1960) found an aneurysm of the membranous septum, II $\mathrm{mm}$ in diameter, at necropsy in a 72-year-old woman with heart failure accompanied by various arrhythmias and conduction disturbances.
The two most recent reports describe histological examinations of the conduction system: Heggtveit (1964) described the case of a 69-year-old man admitted with heart failure and in whom successive electrocardiograms showed atrial and ventricular arrhythmias, an anterior myocardial infarction, then complete heart block. Pathological examination of the heart showed that a portion of the 
bundle of His was related to an aneurysm of the membranous septum whose aperture was $\mathrm{I} \mathrm{cm}$ long. No penetrating portion of the bundle of His could be shown at the level of the central fibrous body. In this case the aneurysmal dilatation of the membranous septum could only have played a subsidiary role. Lastly, the case reported by Harris et al. (1969) was that of a 62-year-old woman suffering from frequent fainting fits. The electrocardiogram showed atrioventricular block with a ventricular rate of $40 \mathrm{a}$ minute. The necropsy revealed that the bundle of His and its bifurcation were located immediately under an aneurysm of the membranous septum and seemed to have been destroyed by a fibrous tissue forming a 'lip' at the lower part of the sac. This fibrous mass was, according to the authors, almost certainly caused by the turbulence of blood flow into the aneurysm (Davies, 1971).

Apart from the observations in aneurysms known to be accompanied by atrioventricular block, research on conduction pathways in congenital aneurysm of the membranous septum was carried out by Hudson (1970) and by Falzi, Fiaccavento, and Micoli (1973). The latter reported five cases which they thoroughly studied with serial sections. The conclusion of their work was that the pathway of the bundle of His is not different from that of normal subjects and the authors question any connexion between the aneurysm and conduction disturbances when present. In our case the bundle of His was surrounded by the lower part of the aneurysm and was, at that level, attenuated, stretched, and atrophic. In the more anterior sections, the aneurysmal sac was directly in contact with the initial subendocardial part of the right branch, which showed signs of degeneration. Moreover in this young child any other cause for atrioventricular block could be excluded. In this case, therefore, despite the conclusions of Falzi and his colleagues, there does appear to be a direct causal link between the aneurysm and damage to the conduction system.

However, it must be considered why, in the first few weeks of life, episodes of supraventricular tachycardia occurred, and why the atrioventricular block progressed only slowly and became complete at the age of 6 months. The hypothesis which we put forward is that the force of each ventricular systole caused traction on the conduction pathways at the level of the neck of the aneurysm. At first the mechanical stimulation caused the appearance of bouts of tachycardia whose origin was the main bundle or its neighbourhood. Later the bundle of $\mathrm{His}$, already stretched, became more and more attenuated and unable to conduct the impulse. In the observations published by Rogers et al. (1952), Larsen and Noer (1960), and Heggtveit (1964), tachycardias of the same type had indeed preceded the appearance of the atrioventricular block. Harris et al. (1969) also suggest the hypothesis of a mechanical strain as being the start of the progressive destruction of the main bundle.

The authors thank Mrs. Fournier and Mrs. Gemehl for their technical assistance.

\section{References}

Clark, R. J., and White, P. D. (1952). Congenital aneurysmal defect of the membranous portion of the ventricular septum associated with heart block, ventricular flutter, Adams-Stokes syndrome and death. Circulation, 5, 725.

Craigie, D. (1843). Observations and cases illustrating the nature of false consecutive aneurism of the heart. Edinburgh Medical and Surgical fournal, 59, 383.

Cuvillier, H. (1974). Bloc auriculoventriculaire par aneurysme du septum membraneux (avec des voies de conduction). Thesis, Lille.

Davies, M. J. (1971). Pathology of Conducting Tissue of the Heart. Butterworths, London.

Falzi, G., Fiaccavento, S., and Micoli, G. (1973). Aspetti morfologici e decorso del sistema di conduzione specifico negli aneurismi della pars membranacea del setto interventricolare. Giornale Italiano di Cardiologia, 3, 6.

Harris, A., Davies, M., Redwood, D., Leatham, A., and Siddons, H. (1969). Aetiology of chronic heart block. A clinico-pathological correlation in 65 cases. British Heart Fournal, 31, 206.

Heggtveit, H. A. (1964). Congenital aneurysm of the membranous septum associated with bundle branch block. American fournal of Cardiology, 14, I 12 .

Hudson, R. E. B. (1970). Cardiovascular Pathology, Vol. III. Edward Arnold, London.

Larsen, K. A., and Noer, T. (1960). Cardiac aneurysm of the membranous portion of the interventricular septum. Acta Medica Scandinavica, 166, 401 .

Legg, J. W. (1876). Aneurysm of the septum of the heart. Transactions of the Pathological Society of London, 27, 104.

Rogers, H. M., Evans, I. C., and Domeier, L. H. (1952). Congenital aneurysm of the membranous portion of the ventricular septum: report of two cases. American Heart fournal, 43, 781.

Requests for reprints to Dr. Cl. Thery, Service de Cardiologie, Cité Hospitalière, place de Verdun, Lille 59000, France. 